\title{
Evaluation on the Express Enterprise's Service Quality of Customers Perception Based on SPSS and Unascertained Measure Model
}

\author{
Guo Caiyun $^{1,2}$ Liu Zhiqiang ${ }^{2 *}$ and Zhang Congyan ${ }^{2}$ \\ ${ }^{1}$ School of Economics and Management, Hebei University of Technology, \\ Tianjin,300401, P. R. China \\ ${ }^{2}$ School of Economics and Management, Hebei University of Engineering, Handan, \\ 056038, P. R. China

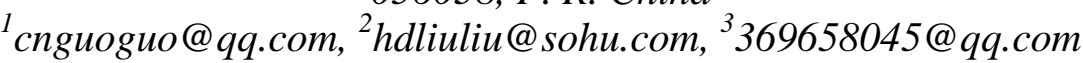

\begin{abstract}
The rapid development of E-commerce has prompted increasing demand for express services. Improving service quality from the customers perception has become an important way for the private express enterprises to face the fierce market competition. This paper summarizes the customers perception service quality theory and the express enterprises' service quality evaluation methods, and establishes an index system of private express enterprises' service quality evaluation from the perspective of the customers perception. The SPSS software is used to detect the feasibility of the established evaluation index system. The information entropy theory is applied to calculate the index weight value, and the evaluation model of private express enterprises' service quality is established by combining the entropy weight with the unascertained measure method. Finally, this paper carries out the empirical analysis based on the JY express enterprise's service quality, and puts forward the relevant countermeasures and suggestions. The purpose of the paper is to provide a new scientific method for the service quality evaluation of the private express enterprises.
\end{abstract}

Keywords: customers perception, service quality, SPSS, unascertained measure model

\section{Introduction}

With the rapid development of the information technology and E-commerce, the social demand of express business is also growing, meanwhile the demand for express enterprises service quality is becoming more and more high. In the express industry, a number of private express enterprises develop very rapidly, but their service quality are uneven. The National Post Office has revealed that the main problems on customers complaint about the express business are the delay of express mail and the poor quality of services. It occupies $76 \%$ of the express business effective complaints. For example, the complaint rate of a private express enterprise was as high as $63.3 \%$ in October 2013. Facing the fierce market competition, private express enterprises urgently need to improve the service quality to win customers. Setting up a relatively reasonable express delivery service quality evaluation system can help the enterprises to measure service quality themselves, and find the problems and the insufficiency. And then the appropriate measures should be taken to improve customer satisfaction and loyalty, so as to enhance enterprise competitiveness. Consequently,in this paper, we discuss the service quality evaluation indexes and methods of the private express enterprises from the perspective of customer perception. 


\section{Literature Review}

Gronroos, a Finland's marketing professor (1982) put forward the concept of the customer perceived service quality. Since then many scholars began to study service quality based on customer perception and achieve remarkable results. Among them, the most representative were SERVQAL model(Parasuraman A, Zeithaml V A, Berry L L, 1988), which measured service quality of customer expectation and the service quality of customer perception after they experience service and then evaluated service quality after compareded them, and SERVPERF model(Cronin J J Jr,Taylor S A,1992), which measured service quality except customer expectations. Erdogan H. Ekiz, Ali Bavik and Huseyin Arasli(2009)considered that customer perceptive service quality was positively correlated with customer satisfaction and repeat purchase, and then they took the car rental for an example to design RENTQVAL model. Deng-Juin Lin, Ing-Cheau Sheu and Jar-Yuan Pai(2009) proved the applicability of the SERVQUAL model in the populations of the Laser to treat myopia operation. Masood H Siddiqui and Tripti Ghosh Sharma(2012) studied customer perceived service quality evaluation of Latitude in the life insurance industry. Kwek Choon Ling,Lau Teck Chai and Tan Hoi Piew (2010) analyzed the limitations of SERVQUAL scale in theory and operation, then they tried to use "from the inside to outside"and "outside"approaches to do empirical study about Malaysia private colleges students perceived service quality. Many Chinese scholars introduced the customer perceived service quality into the express industry. Zhu Meihong, Miu Shengtao and Zhuo Jun(2011) carried out exploratory and confirmatory factors analysis on the SERVQUAL scale, and built new scale to measure the express delivery service quality. Yu Baoqin and Du Guangwei(2013) designed the service quality evaluation system of the online shopping express enterprise, and used the fuzzy analytic hierarchy process to evaluate it. Liu Kaidi, Pang Yanjun and Sun Guangyong(1999) evaluated the urban environment quality by using unascertained measure method.

To sum up, foreign scholars study customer perceived service quality earlier, they mainly focus on the perceived service quality scale validation, and rarely involve in several kind of evaluation methods. Domestic scholars' researches about the customer perception evaluation indexes of express delivery service quality are lack of considering the customer 'respect' factor. And the mostly evaluation methods they have used are AHP and fuzzy comprehensive evaluation methods. As is well-known, the shortage of the AHP is strong subjectivity and high consistency of index requirements, while the disadvantage of existing fuzzy comprehensive evaluation method (such as $\mathrm{M}(\bullet,+)$ ) can make the evaluation indexes that have no effect on the classification involve in calculation. Moreover, it is will lead to the evaluation results distortion. So, in this paper we will combine entropy weight method with unascertained measure to construct the comprehensive evaluation model, in order to better solve the above problems.

\section{Establishing of Evaluation Index System for Customers Perception Service Quality}

\subsection{Establishing of the Index System}

With the increasing improvement of requirements for service quality, customer care more and more about whether sincere service afforded by enterprise and careful care they offered, and whether real respect the enterprise given. In this paper, these factors are classified as "respect". The factor is becoming increasingly important in evaluating the express enterprise service quality, moreover it affect the degree of customer perception of service quality directly. On the basis of SERVQUAL scale and the tenth reference, this paper adds the dimension of "respect" to construct service quality evaluation index system based on customer perception. The specific content is shown in Table 1. 


\section{Table 1. The Express Enterprise's Service Quality Evaluation Index System Based on Customers Perception}

\begin{tabular}{|c|c|c|}
\hline & $\begin{array}{c}\text { First level } \\
\text { indexes }\end{array}$ & Second level indexes \\
\hline $\begin{array}{l}\text { The express } \\
\text { enterprise } \\
\text { service } \\
\text { quality } \\
\text { evaluation } \\
\text { index } \\
\text { system } \\
\text { based on } \\
\text { customer } \\
\text { perception }\end{array}$ & Tangibility $\mathrm{A}_{2}$ & $\begin{array}{l}\text { Enterprise can offer customers specific care } \mathrm{A}_{11} \\
\text { Express service personnel can offer customer personalized attention } \mathrm{A}_{12} \\
\text { Express service personnel know well about the customer needs } \mathrm{A}_{13} \\
\text { Enterprise put what customer care most in mind } \mathrm{A}_{14} \\
\text { Enterprise arranging convenient service for customer by setting up service } \\
\text { places and appropriate business hours and providing door to door service } \mathrm{A}_{15} \\
\text { Enterprise has clear LOGO } \mathrm{A}_{21} \\
\text { Enterprise service personnel wear uniform with LOGO and chest card } \mathrm{A}_{22} \\
\text { Express service personnel can be trusted by customer } \mathrm{A}_{31} \\
\text { Customer can feel rest assured and security when trade with enterprise } \mathrm{A}_{32} \\
\text { Enterprise can complete what they promise to customer on time } \mathrm{A}_{41} \\
\text { Enterprise can offer posting express in their promise time } \mathrm{A}_{42} \\
\text { Enterprise can tell time exactly when provide service for customer } \mathrm{A}_{43} \\
\text { Enterprise can provide timely service for customer } \mathrm{A}_{44} \\
\text { Enterprise express will not harm to the safety of country organization and } \\
\text { citizen } \mathrm{A}_{51} \\
\text { Enterprise will take several measures to protect the express and service } \\
\text { personnel safety from harm } \mathrm{A}_{52} \\
\text { Enterprise will not leak and misappropriate the related information of senders } \\
\text { and recipients and expresses except in accordance with the requirements of } \\
\text { national security and public security organs } \mathrm{A}_{53} \\
\text { The attitude of express service personnel is warm when they offer service, } \\
\text { they can give customer really care rather than simply to complete task } \mathrm{A}_{61} \\
\text { Express service personnel service with kind language and give customer } \\
\text { family - like feeling } \mathrm{A}_{62} \\
\text { Enterprise can respect customer' s privacy and personality } \mathrm{A}_{63}\end{array}$ \\
\hline
\end{tabular}

\subsection{Verification of the Index System}

According to the index system of Table 1, the customers of JY express enterprise are taken as inquisition object, including apart of university teachers and students and residents of nearby communities, sends out questionnaires 150 , recycles 99 , effectiveness is $66 \%$. Then the structure validity and reliability of questionnaires are tested with the software SPSS19.0. When the structure validity KMO generally greater than $60 \%$ and $\mathrm{P}$ less than 0.001 , the reliability coefficient $\alpha$ is showed as follow:

$$
\alpha=\frac{\mathrm{k}}{k-1} \times\left(1-\frac{\sum_{i=1}^{k} s_{i}^{2}}{s_{T}^{2}}\right)
$$

In the formula (1), $\mathrm{k}$ is the total number of questionnaire, $s_{i}^{2}$ is the score for the variance of question $\mathrm{i}, s_{T}^{2}$ is the total scale of variance, and usually $a>0.7$. The testing result of the structure validity and reliability of questionnaire are shown in Table 2 and Table 3. 
Table 2. The Questionnaire Validity Testing Table

\begin{tabular}{lrr}
\hline \multicolumn{3}{c}{ KMO and Bartlett's Test } \\
\hline Kaiser-Meyer-Olkin Measure of Sampling Adequacy. & .766 \\
\multirow{3}{*}{ Bartlett's Test of Sphericity } & Approx. Chi-Square & 618.657 \\
& df & 171 \\
& Sig. & .000 \\
\hline
\end{tabular}

According to Table 2, $\mathrm{KMO}=0.766, \mathrm{p}=0.000$, the questionnaire is suitable for factor analysis. It also shows that the dimension of the questionnaire is reasonable and can reflect what properties the customer want to know.

Table 3. The Questionnaire Reliability Analysis Table

\begin{tabular}{|c|c|c|c|}
\hline \multicolumn{4}{|c|}{ Reliability Statistics } \\
\hline \multirow[t]{2}{*}{$\begin{array}{l}\text { Cronbach's } \\
\text { Alpha }\end{array}$} & & & $\mathrm{N}$ of Items \\
\hline & .963 & .967 & 19 \\
\hline
\end{tabular}

The Table 3 shows that the overall internal consistency is very high, $a=0.963$, which indicates that the questionnaire has higher reliability.

The analysis of the testing results of the questionnaire survey shows that the design of questionnaire is reasonable, it can reflect the survey questions.

\section{Service Quality Evaluation Model Based on Entropy Weight and Unascertained Measure}

Denoted by $\mathrm{X}$ as evaluation of the object space and $x_{1}, x_{2}, \cdots, x_{n}$ represents $\mathrm{n}$ evaluation objects, so $X=\left\{x_{1}, x_{2}, \cdots, x_{n}\right\}$, each object $x_{i}$ has $\mathrm{m}$ evaluation indexes such as $I_{1}, I_{2}, \cdots, I_{m} . x_{i j}$ represents the observation value of object $x_{i}$ under the index $I_{j}$.Supposing $C=\left\{C_{1}, C_{2}, \cdots, C_{k}\right\}$ acts as level evaluation space, where $C_{k}(1 \leq k \leq K)$ is the $k$ th evaluating grade, that means $C_{1}>C_{2}>\cdots>C_{k}$ or $C_{1}<C_{2}<\cdots<C_{k}$. Let the degree which $x_{i j}$ makes $x_{i}$ belong to the $k$ th evaluation grade $C_{k}$ is $\mu_{i j k}=\mu\left(x_{i j} \in C_{k}\right)$. Then $\mu$ is a measurement result of the degree, and as a measurement it must satisfy three usual measurement rules: "nonnegative-bound, additive and normalization",the unascertained measure $\mu$ satisfies:

$$
\begin{aligned}
& 0 \leq \mu\left(x_{i j} \in C_{k}\right) \leq 1 \text { and } \mu\left(x_{i j} \in \bigcup_{k=1}^{K} C_{k}\right)=\sum_{k=1}^{K} \mu\left(x_{i j} \in C_{k}\right) \text { and } \mu\left(x_{i j} \in C\right)=1 \text {, where } \\
& i=1,2, \cdots, n ; j=1,2, \cdots, m ; k=1,2, \cdots, K
\end{aligned}
$$

\subsection{Calculation of Single Index Unascertained Measure}

Generally the single index unascertained measure matrix can be constructed by two methods:The one is to use the method of unascertained measure functions, including linear, quadratic, sinusoidal and exponential curve, and the other can also be determined by score when the membership function or condition is limited, and when simplify processing. Here, the single index unascertained measure matrix is identified by calculating the scores of respondents, which the degree that $x_{i j}$ makes $x_{i}$ belong to the 
$k t h$ evaluation grade $C_{k}$. The single index unascertained measure matrix is showed as follow:

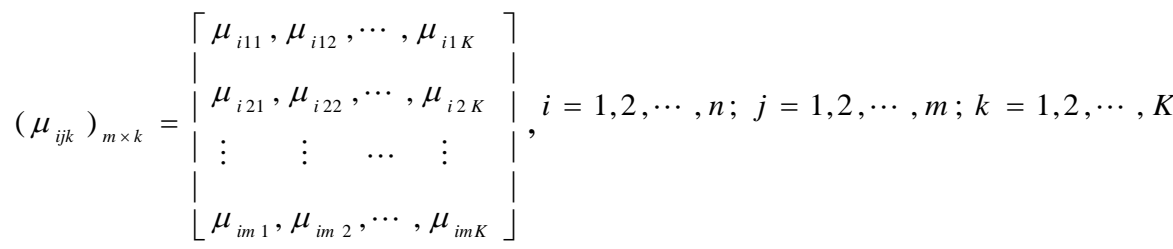

\subsection{Weight Determination by the Entropy Theory}

There are several ways to calculate index weights, such as the Delphi method, AHP and Entropy method and so on. The entropy is a excellent method to reduce the affect of personal subjectivity on the weight values determined. Calculation is showed as follows:

$$
\begin{aligned}
& H(j)=-\sum_{k=1}^{K} \mu_{i j k} \bullet \lg \mu_{i j k} \\
& v_{j}=1-\frac{1}{\lg K} H(j)=1+\frac{1}{\lg K} \sum_{k=1}^{K} \mu_{i j k} \lg \mu_{i j k} \\
& w_{j}=\frac{v_{j}}{\sum_{j=1}^{m} v_{j}}, \quad\left(0 \leq w_{j} \leq 1, \sum_{j=1}^{m} \mathrm{w}_{j}=1\right)
\end{aligned}
$$

So the vector $w=\left(w_{1}, w_{2}, \cdots, w_{j}\right)$ is the index weight vector of the attribute set $I_{j}$ about the sort of $x_{i}$.

\subsection{Calculation of the Multi-indexes Synthetic Measure}

Unascertained measurement vector $\mu_{i}$ of the evaluation vector $x_{i}$ can be calculated by the single index unascertained measure $\mu_{i j k}$ and index weight vector $w$.And using the following formula:

$\mu_{i k}=\sum_{j=1}^{m} w_{j} \cdot \mu_{i j k} \quad(i=1,2, \cdots, n, \quad k=1,2, \cdots, K)$

And the vectors $\mu_{i}=\left(\mu_{i 1}, \mu_{i 2}, \cdots, \mu_{i K}\right)^{T}$ respect the multi-indexes synthetic evaluation vectors.

\subsection{Judgment of the Evaluation Result}

Because of the evaluation space order, this paper uses confident degree to identify the evaluation result. $\lambda(0.6<\lambda<0.8)$ is defined as confident degree.

$$
k_{0}=\min _{k}\left(k: \sum_{i=1}^{k} \mu_{i} \geq \lambda, 1 \leq k \leq K\right)
$$

So evaluation object $C_{k}>C_{k+1}$ belongs to level $\mathrm{K}_{0}$ and the confident degree is not lower than $\lambda$. 


\section{Empirical Analysis}

The paper takes JY express enterprise in Handan as an example to analyze express enterprise service quality with above models. Firstly evaluation degree assemble must be set. This paper divides the evaluation degree of service quality of JY express enterprise into five levels. They are $\{$ better, good, common, bad, worse $\}$. And the evaluation degree assemble is defined as $\mathrm{C}$, and $C=\left\{C_{1}, C_{2}, C_{3}, C_{4}, C_{5}\right\},(k=1,2,3,4,5)$. The evaluation degree assemble is ordered, usually the evaluation degree $C_{k}$ is better than the $C_{k+1}$, that is $C_{k}>C_{k+1}$.

\subsection{Calculating of the Single Index Unascertained Measure}

According to the results of the questionnaires, the paper calculated the corresponding grade frequency of the various secondary indicators as single index unascertained membership. The results are showed in Table 4.

Table 4. Single Index Unascertained Membership

\begin{tabular}{ccccccc}
\hline $\begin{array}{c}\text { First level } \\
\text { indexes }\end{array}$ & $\begin{array}{c}\text { Second level } \\
\text { indexes }\end{array}$ & Better & Good & Common & Bad & Worse \\
\hline & $\mathrm{A}_{11}$ & 0 & 0.1104 & 0.4939 & 0.3497 & 0.046 \\
& $\mathrm{~A}_{12}$ & 0.0545 & 0.1939 & 0.3713 & 0.2818 & 0.0985 \\
$\mathrm{~A}_{1}$ & $\mathrm{~A}_{13}$ & 0.028 & 0.0994 & 0.4565 & 0.3075 & 0.1086 \\
& $\mathrm{~A}_{14}$ & 0.069 & 0.1595 & 0.3758 & 0.2577 & 0.138 \\
& $\mathrm{~A}_{15}$ & 0.1548 & 0.5397 & 0.2314 & 0.0476 & 0.0265 \\
& $\mathrm{~A}_{21}$ & 0.1473 & 0.4475 & 0.2387 & 0.1392 & 0.0273 \\
$\mathrm{~A}_{2}$ & $\mathrm{~A}_{22}$ & 0.1247 & 0.3989 & 0.2908 & 0.1579 & 0.0277 \\
& $\mathrm{~A}_{31}$ & 0.0632 & 0.3933 & 0.3638 & 0.1516 & 0.0281 \\
$\mathrm{~A}_{3}$ & $\mathrm{~A}_{32}$ & 0.0868 & 0.3636 & 0.4532 & 0.0826 & 0.0138 \\
& $\mathrm{~A}_{41}$ & 0.0644 & 0.3319 & 0.3705 & 0.1974 & 0.0358 \\
& $\mathrm{~A}_{42}$ & 0.0749 & 0.5437 & 0.3398 & 0.0416 & 0 \\
$\mathrm{~A}_{4}$ & $\mathrm{~A}_{43}$ & 0.1152 & 0.2162 & 0.4879 & 0.1451 & 0.0356 \\
& $\mathrm{~A}_{44}$ & 0.0763 & 0.3616 & 0.3757 & 0.1441 & 0.0423 \\
& $\mathrm{~A}_{51}$ & 0.3586 & 0.3702 & 0.1889 & 0.0694 & 0.0129 \\
& $\mathrm{~A}_{52}$ & 0.1537 & 0.5782 & 0.184 & 0.071 & 0.0131 \\
$\mathrm{~A}_{5}$ & $\mathrm{~A}_{53}$ & 0.1278 & 0.4205 & 0.1989 & 0.1534 & 0.0994 \\
& $\mathrm{~A}_{61}$ & 0.223 & 0.5598 & 0.1327 & 0.0262 & 0.0583 \\
& $\mathrm{~A}_{62}$ & 0.1037 & 0.2651 & 0.4135 & 0.1383 & 0.0794 \\
& $\mathrm{~A}_{63}$ & 0.053 & 0.2828 & 0.3505 & 0.2474 & 0.0663 \\
\hline $\mathrm{A}_{6}$ & & & & & &
\end{tabular}

\subsection{Calculating of the Index Weight and Multi-Indexes Synthetic Measure}

Based on the statistical data of the table 4, according to the(2) (4), and applying the entropy method, we can get the each second index weight vector: $w_{1}=(0.2096,0.1963$, $0.2032,0.1957,0.1952), w_{2}=(0.4734,0.5266), w_{3}=(0.4856,0.5144), w_{4}=(0.2450$, $0.2642,0.2450,0.2458), w_{5}=(0.3269,0.3495,0.3236)$ 和 $w_{6}=(0.3545,0.319,0.3265)$. 
Based on the statistical data of evaluated objects given by questionnaire survey (supposing as sample 'empathy $\mathrm{A}_{1}$ '), here is the single index unascertained measure matrix $\mu_{1 j k}$ given as following:

$\left(\mu_{1 j k}\right)_{5 \times 5}=\left[\begin{array}{ccccc}0 & 0.1104 & 0.4939 & 0.3497 & 0.046 \\ 0.0545 & 0.1939 & 0.3713 & 0.2818 & 0.0985 \\ 0.028 & 0.0994 & 0.4565 & 0.3075 & 0.1086 \\ 0.069 & 0.1595 & 0.3758 & 0.2577 & 0.138 \\ 0.1548 & 0.5397 & 0.2314 & 0.0476 & 0.0265\end{array}\right]$

According to the formula (5), the single index unascertained measure vector can be computed:

$\mu_{11}=w_{1} \times\left(\mu_{115}\right)_{5 \times 5}=\left(\begin{array}{lllll}0.0601 & , 0.218 & 0.3879 & , 0.2508 & , 0.0832\end{array}\right)$

Repeating above calculating process, we can get each single index unascertained measure vector A2 A6: $(0.1354,0.4219,0.2661,0.149,0.0275),(0.0753,0.378,0.4098$, $0.1161,0.0207) 、(0.0825,0.3668,0.3924,0.1303,0.2789),(0.2123,0.4592,0.1904$, $0.0971,0.041)$ and $(0.1294,0.3754,0.2934,0.1342,0.0676)$. So,we can get a new unascertained measure matrix $\mu_{1}$ :

$\mu_{1}=\left[\begin{array}{lllll}0.0601 & 0.218 & 0.3879 & 0.2508 & 0.0832 \\ 0.1354 & 0.4219 & 0.2661 & 0.149 & 0.0275 \\ 0.0753 & 0.378 & 0.4098 & 0.1161 & 0.0207 \\ 0.0825 & 0.3668 & 0.3924 & 0.1303 & 0.2789 \\ 0.2123 & 0.4592 & 0.1904 & 0.0971 & 0.041 \\ 0.1294 & 0.3754 & 0.2934 & 0.1342 & 0.0676\end{array}\right]$

The first index weight vector has been known: $w=(0.1677,0.1648,0.1684,0.1679$, $0.165,0.1662$ ), according to $\mu_{1}$ and the formula (5), we can calculate multi-indexes unascertained synthetic measure vector $\mu$ :

$$
\mu=w \times \mu_{1}=\left(\begin{array}{lllll}
0.1155 & , 0.3695 & , 0.324,0.1464,0.0446
\end{array}\right)
$$

\subsection{Determining of the Membership Level and Confidence Degree}

Identify the level of multi-indexes unascertained measure of the JY express company service quality according to the confident degree. Get the value of the confident degree $\lambda=0.8$.According to the formula (6), the result can be obtained: $0.1155+0.3695+0.324=0.809>0.8$. According to the identification criteria of confidence levels, we can know $k_{0}=3$, the JY express enterprise's service quality belongs to the third evaluation level "common" and the confidence level is more than $80 \%$. The result is also consistent with the reality of JY express company service quality.

\section{Suggestions for the Express Enterprise to Enhance Service Quality}

\subsection{Enhance Customer Perceived Service Quality Awareness}

In the customer-centric service enterprises, how to provide service is as important as what kind of service is provided So,in order to improve their service quality, the express enterprises should strongly advocate the customer perceived service concept, improve the 
service methods, fully consider how to reduce the distance with the customer, improve customer service awareness, thus raise the service quality.

\subsection{Innovate Customer Perceived Service Quality Methods}

The enterprise should create and maintain good reputation for service quality, because the experience of others will impact more on customers when they make a choice. If they have a good service reputation, the customers will have a good expectation for the enterprises' service. The enterprise service personnel should be sincere and enthusiastic when they provide service. And when they communicate with customers, the enterprise service personnel must be kind to give customers a feeling of family. What's more, the express enterprise must properly protect customers' private information and respect their privacy and personality.During the holidays, the enterprise can provide the girts with the corporate image for different levels of customers, and invite customers to experience personalized services.

\subsection{Improve Customer Perceived Service Quality Evaluation Indexes}

To design the evaluation indexes reasonably is the premise for the express enterprises to evaluate their service quality accurately. Besides the basic indexes, such as the service timeliness, safety, assurance and tangibility, the more importance for the enterprises to increase customer perceived is to try to add customer perceived service index, such as "respect for nature". Additionally,when choosing appropriate evaluation methods, we should try to consider the combination of subjective and objective. All in all, the enterprises can enhance the scientificalness and effectiveness of the evaluation results by constantly improve the service quality evaluation indexes.

\subsection{Establish the Customer Feedback Information by Network}

In this way, the express enterprises can take advantage of the enterprise's web site to set up the customer message board or the evaluation area of the service quality, in order to let the customer to evaluate the perception of service in a timely and objectively put forward the proposals, make the enterprise in the first time to know consumers' response, and correct the shortcomings of their own service in time, so as to continuously improve service quality and customer satisfaction.

\section{Conclusion}

With the gradually expanding demands and the increasingly fierce competition of the express delivery market, many private express enterprises need to win customers by the intimate service and they also need sincere service for the customers to perceive. This paper optimizes the private express enterprise service quality evaluation index system from the customer perception perspective and verifies the feasibility. Calculating the index weight with the entropy can fully avoid the influence of subjective factors. Furthermore, introducing unascertained measure in the service quality evaluation can better solve the problem of multi-index comprehensive evaluation and make a more reliable result. It is also able to provide a scientific method for the private express enterprises to evaluate the service quality. The application of SPSS and unascertained measure model is also helpful for evaluating the service quality and promoting the core competitiveness of private express enterprises.

\section{References}

[1] J. J. Jr Cronin and S. A. Taylor, "Measuirng Service Quality:A Reexamination and Extension", Journal of Marketing, vol. 56 , no. 1, (1992), pp. 55-68. 
[2] L. Deng-Juin, S. Ing-Cheau and P. Jar-Yuan, "Measuring Patient's Expectation and the Perception of Quality in LASIK services", Health and Quality of Life Outcomes, no. 7, (2009), pp. 63-71.

[3] E. H. Ekiz, A. Bavik and H. Arasli, "RENTQUAL: A new Measurement Scale for Car rental services", Tourism: An International Interdisciplinary Journal, vol. 57, no. 2, .(2009), pp. 135-153.

[4] C. Gronroos, "Strategic Management and mMarketing in the service sector", Helsinki, Finland:Swedish School of Economics and Administration, (1982).

[5] K. C. Ling, L. T. Chai and T. H. Piew, "The'Inside-out'and'Outside-in Approaches on Students' Perceived Service Quality: An Empirical Evaluation”, Management Science and Engineering, vol. 4, no. 2, (2010), pp. 1-26.

[6] L. Kaidi, P.Yanjun and S.Guangyong, "Evaluation on Unascertained Measure of Urban Environmental Quality",Systems Engineering Theory and Practice, no. 12, (2009), pp. 52-57.

[7] M. H. Siddiqui and T. G. Sharma, "Measuring the Customer Perceived Service Quality for Life Insurance Services: An Empirical Investigation", International Business Research, vol. 3, no. 3, (2012), pp. 171-186.

[8] A. Parasuraman, V. A. Zeithaml and L. L. Berry, "SERVQVAL:A Multiple Item Scale for Measuring Consumer Perceptions of Service Quality”, Journal of Retailing, vol. 64, no. 1, (1988), pp. 12-40.

[9] Y. Baoqin and D. Guangwei, "Study Fuzzy Evaluation of online Shopping Delivery Service Quality based on SERVQUAL model”, Industrial Engineering, vol. 16, no. 2, (2013), pp. 127-133.

[10] Z. Meihong, M. Shengtao and Z. Jun, "Empirical Study on Chinese Express Industry Service Quality Evaluation on SERVQUAL", Technology Management Research, vol. 8, (2011), pp. 38-45.

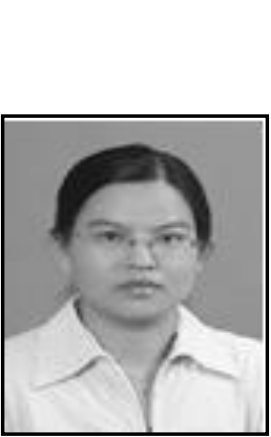

\section{Authors}

Guo Caiyun, she received her M. of Management (2004) from Hebei University of Technology. Now she is an associate professor of management science and engineering at Economics Management Department, Hebei University of Engineering, and a PhD student of Hebei University of Technology. Her current research interest is business management.

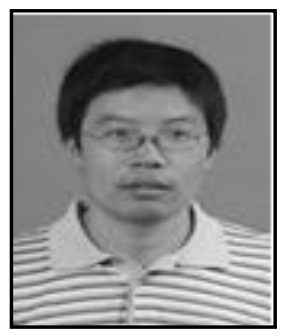

Liu Zhiqiang, he received his M. of Management (2003) from Yanshan University. Now he is an associate professor of management science and engineering at Economics Management Department, Hebei University of Engineering. His current research interests include management decision and logistics engineering.

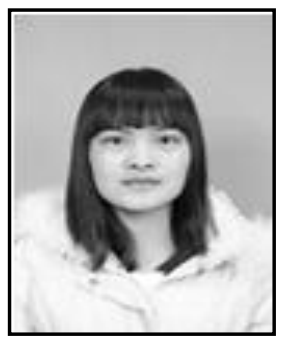

Zhang Congyan, she received her Bachelor's Degree of business management from university in 2012. Now she is a full-time master graduate student of Logistics Engineering, Hebei University of Engineering. Her current research interests include logistics and supply chain management. 
International Journal of $\mathrm{u}-$ and $\mathrm{e}-$ Service, Science and Technology Vol.9, No. 3 (2016) 